\section{When Worlds Collide: Autoimmunity and Atherosclerosis}

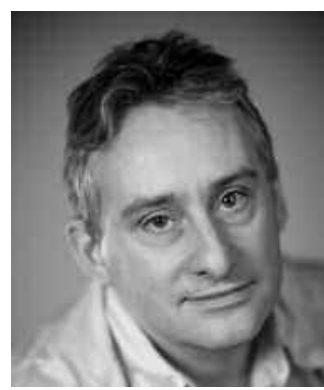

It has been known for many years that individuals with autoimmune diseases such as systemic lupus erythematosus (SLE) and rheumatoid arthritis (RA) are at increased risk of cardiovascular disease ${ }^{1,2}$. While it is unclear whether the presence of autoantibodies is responsible for the increased risk, such a possibility seems inherently plausible since at least some autoantibodies (such as lupus anticoagulant and antiphospholipid antibodies, but also more recently anti-hsp60 antibodies $^{3}$ ) are known to modulate clotting cascades and are associated with increased risk of thrombus formation.

In parallel, it has been known since the 1980s that autoantibodies against oxidized lipoprotein epitopes are prevalent in subjects with clinically significant atherosclerosis ${ }^{4}$. There are several possible causes of such an association: lipid oxidation is more common among individuals with atherosclerosis, so increased presence of the epitope could increase prevalence of antibodies. Alternatively, changes in immune system regulation associated with a systemic proinflammatory status might increase the likelihood of an autoimmune response against oxidized lipoproteins, or indeed against other selfantigens such as heat shock proteins.

Irrespective of the pathways responsible, these autoantibodies associated with atherosclerosis could merely mark processes that are pathogenic, or they could themselves modulate disease progression. There is considerable debate as to the role of such autoantibodies, with the possibility that IgG against oxidized low density lipoprotein (LDL) are pathogenic while $\operatorname{IgM}$ antibodies against similar epitopes are protective ${ }^{5}$.

Until recently, however, these 2 parallel spheres of investigation were largely separated by the nature of the self-antigens typically associated with each disease. Indeed, the focus of much of the research has been on the epitope specificity of the autoantigen pools, rather than on the immunoregulatory mechanisms controlling autoantibody formation, thereby further emphasizing this separation.

In the last decade, however, even this distinction has begun to blur: individuals with RA and SLE have higher levels of autoantibodies against oxidized LDL, even in the absence of overt cardiovascular disease ${ }^{6}$. Similarly, several studies have suggested that antinuclear antibodies (ANA), antiphospholipid antibodies, and anticyclic citrullinated peptide antibodies (CCP), each more typically associated with autoimmune disorders such as SLE and RA, are more prevalent and at higher titer among individuals with cardiovascular disease ${ }^{7,8}$.

In this issue of The Journal Liang and colleagues ${ }^{9}$ take these findings a step further, demonstrating, in the largest study of its kind to report, that a positive test for ANA or rheumatoid factor (RF) is associated with a small, but significant, increase in future risk of both cardiovascular events and total mortality. Importantly, their pseudoprospective study design encompassed individuals both with and without an existing diagnosis of rheumatic diseases, and the association with cardiovascular events was significant in both subgroups. While this falls short of demonstrating an association between rheumatoid autoantibodies and cardiovascular disease in the general population (since all the subjects recruited into Liang's study were being tested for rheumatoid autoantibodies on clinical grounds), it does further suggest that autoantibodies are associated with cardiovascular disease irrespective of their epitope (or, at least, that a wider range of epitopes may be more important than had previously been thought).

A subgroup of the subjects studied by Liang and colleagues were also tested for anti-CCP antibodies, and again a trend to increased cardiovascular events among those with anti-CCP antibodies was observed (this time with a 3-fold hazard ratio), although this was not statistically significant most likely due to the smaller sample size. It will be interesting to see if this trend is robust in larger future studies.

A number of questions remain unanswered: ANA was assessed by enzyme immunoassay using whole-cell lysate. Such assays often correlate poorly with the gold-standard immunofluorescence detection of ANA on fixed-cell preparations, in part due to the presence of false-positive detection of antibodies against cytoskeletal, and other cytoplasmic, epitopes, which could plausibly be elevated in atherosclerosis independently of true ANA. As a result, the present study says nothing about which nuclear antigens may be involved (although our earlier cross-sectional study ${ }^{10}$ suggested that antinucleolar patterns were most strikingly associated with the presence of coronary atherosclerosis).

Despite the pseudo-prospective nature of the association,

See Autoantibodies and risk of CV events, page 2462

Personal non-commercial use only. The Journal of Rheumatology Copyright (C) 2009. All rights reserved. 
it is also unclear whether the ANA and RF antibodies are involved in the pathogenesis of the vascular disease, or are markers for defects in immunoregulatory pathways that are shared between rheumatoid and atherosclerotic disease. The latter seems more plausible. Among patients with RA, titers of autoantibodies did not correlate with increased risk of cardiovascular disease ${ }^{11}$. Similarly, studies of vasectomy have provided an indirect experimental investigation of this issue: vasectomy increases the incidence of anti-dsDNA autoantibodies, presumably because of increased leakage of normally cryptic nuclear contents during resorption of DNA-rich spermatozoa in the epididymis. Although initial studies in primates suggested this accelerated vascular lipid lesion formation, two studies in large US cohorts ruled out any increase in atherogenesis or cardiovascular events in the human population ${ }^{12,13}$. Circumstantial though it is, this argument suggests that, at least for anti-dsDNA antibodies, there is no direct pathogenic role.

All this evidence adds up to one conclusion: autoantibody formation is a common component of both autoimmune diseases and atherosclerosis. There is no clear separation of the portfolio of epitopes seen in one disease versus the other: antibodies to oxidized lipoproteins are seen in rheumatoid disease and antibodies against intracellular antigens are seen in cardiovascular disease. Perhaps it matters less what the antibodies have been raised against, than the misregulation of the immune system that allowed such autoantibodies to be developed at all? Understanding the pathogenesis of both diseases may eventually be aided by an understanding of the common mechanisms both share, which result, in both cases, in the association with autoantibodies.

What might such a common mechanism be? A good candidate is the clearance of apoptotic cell debris by tissue macrophages. Deficiency in complement factors important for the recognition of apoptotic bodies leads to SLE-like disease $^{14}$, at least in part as a result of slowed clearance of cell debris, allowing previously cryptic intracellular antigens time to be exposed to the immune system. Similarly, apoE ${ }^{15}$ and lactadherin ${ }^{16}$ have been implicated in the regulation of macrophage clearance of cell debris, leading to reduced uptake of apoptotic cell bodies in atherosclerosis. It is possible that the same process is important in these very different diseases, leading in both cases to autoantibody development.

When strands of research into two ostensibly very different fields begin to coalesce, it can often highlight fundamental biological processes important in both. The study by Liang and colleagues ${ }^{9}$ closes the gap between autoimmune diseases and atherosclerosis and highlights mechanisms, such as clearance of apoptotic cell debris, that are likely to be important in the pathogenesis of both diseases. The relatively modest effect size seen in these studies suggests that measuring ANA clinically as part of the diagnostic paradigm for cardiovascular disease is unlikely to be useful. But the insight into the biological mechanisms behind the disease may have a lasting impact.
DAVID J. GRAINGER, $\mathrm{PhD}$

Department of Medicine,

Cambridge University,

Box 157 Addenbrooke's Hospital,

Cambridge, CB2 0QQ, United Kingdom

Address correspondence to Dr. Grainger.E-mail: djg15@cam.ac.uk

\section{REFERENCES}

1. Gabriel SE, Crowson CS, Kremers HM, Doran MF, Turesson C, O'Fallon WM, et al. Survival in rheumatoid arthritis: a population based analysis of trends over 40 years. Arthritis Rheum 2003;48:54-8.

2. Doria A, Iaccarino L, Sarzi-Puttini P, Atzeni F, Turriel M, Petri M. Cardiac involvement in systemic lupus erythematosus. Lupus 2005;14:683-6.

3. Dieude M, Gillis MA, Theoret JF, Thorin E, Lajoie G, Levine JS, et al. Autoantibodies to heat shock protein 60 promote thrombus formation in a murine model of arterial thrombosis. J Thromb Haemost 2009;7:710-9.

4. Yla-Herttuala S. Macrophages and oxidised low density lipoproteins in the pathogenesis of atherosclerosis. Ann Med 1991;23:561-7.

5. Lewis MJ, Makil TH, Ehrenstein MR, Boyle JJ, Botto M, Haskard DO. Immunoglobulin $\mathrm{M}$ is required for protection against atherosclerosis in low-density lipoprotein receptor-deficient mice. Circulation 2009;120:417-26.

6. Matsuura E, Lopez LR. Autoimmune-mediated atherothrombosis. Lupus 2008;17:878-87.

7. Marai I, Schecter M, Langevitz P, Gilburd B, Rubenstein A, Matssura E, et al. Anti-cardiolipin antibodies and endothelial function in patients with coronary artery disease. Am J Cardiol 2008;101:1094-7.

8. Gerli R, Bocci E, Sherer Y, Vaudo G, Moscatelli S, Shoenfeld Y. Association of anti-cyclic citrullinated peptide antibodies with subclinical atherosclerosis in patients with rheumatoid arthritis. Ann Rheum Dis 2008;67:724-5.

9. Liang KP, Kremers HM, Crowson CS, Snyder MR, Therneau TM, Roger VL, et al. Autoantibodies and the risk of cardiovascular events. J Rheumatol 2009;36:2462-9.

10. Grainger DJ, Bethell HW. High titres of serum anti-nuclear antibodies, mostly directed against nucleolar antigens, are associated with the presence of coronary atherosclerosis. Ann Rheum Dis 2002;61:110-4.

11. Pereira I, Laurindo I, Burlingame R, Anjos L, Viana V, Leon E, et al. Autoantibodies do not influence development of atherosclerotic plaques in rheumatoid arthritis. Joint Bone Spine 2008;75:416-21.

12. Manson JE, Ridker PM, Spelsberg A, Ajani U, Lotufo PA, Hennekens CH. Vasectomy and subsequent cardiovascular disease in US physicians. Contraception 1999;59:181-6.

13. Coady SA, Sharrett AR, Zheng ZJ, Evans GW, Heiss G. Vasectomy, inflammation, atherosclerosis and long term follow-up for cardiovascular diseases: no associations in the Atherosclerosis in Communities Study. J Urol 2002;167:204-7.

14. Truedsson L, Bengtsson AA, Sturfelt G. Complement deficiencies and systemic lupus erythematosus. Autoimmunity 2007;40:560-6.

15. Grainger DJ, Reckless J, McKilligin E. Apolipoprotein E modulates clearance of apoptotic bodies in vitro and in vivo resulting in a systemic pro-inflammatory state in apolipoprotein E-deficient mice. J Immunol 2004;173:6366-75.

16. Ait-Oufella H, Kinugawa K, Zoll J, Simon T, Boddaert J, Heeneman $\mathrm{S}$, et al. Lactadherin deficiency leads to apoptotic cell accumulation and accelerated atherosclerosis in mice. Circulation 2007;115:2168-77.

J Rheumatol 2009;36:2378-9; doi:10.3899/jrheum.091027 